\section{Involuntary admission in Ireland}

Putkonen \& Völlm (Psychiatric Bulletin, March 2007, 31, 101-103) are not entirely correct in their assertion that Ireland and Finland are alike in their non-requirement for non-medical authorities to be part of the decision-making process for involuntary admissions. Although in Ireland the initial process requires a medical practitioner to recommend an involuntary admission and a consultant psychiatrist to authorise it, the application is usually made by a non-medical person. Also since the Mental Health Act 2001 was fully implemented in November 2001 there is now a barrister-at-law, a layperson and a solicitor, as well as an additional two psychiatric consultants, involved in the review process which automatically follows each involuntary admission.

The new Act brought Ireland into line with its obligations under the European Convention on Human Rights and Fundamental Freedoms and with the European Convention on Human Rights Act 2003.

Guy Molyneux Specialist Registrar in Psychiatry, Psychiatric Unit, Adelaide and Meath Hospital, Tallaght, Dublin 24, Ireland, email: guymolyneux@ eircom.net

doi: $10.1192 / p b .31 .7 .273$

\section{Reasons for entering staff grade posts}

I was surprised that Fung et al (Psychiatric Bulletin, February 2007, 31, 76) did not find non-availability of a National Training Number (NTN) to be a primary reason for entering staff grade and associate specialist grade (SAS) posts. I passed the MRCPsych part II in June 2006 following which there were no NTNs available locally. I was aware that a few candidates were applying before results came out and in retrospect I wish this is something I had pursued more actively. However, at that time I could not have known the intensity of competition for NTNs that would be precipitated by the approach of run-through training.

It was apparent that I would not secure a higher training post before the senior house officer rotation ended and therefore I applied for a staff grade post locally. Fung et al cite pay protection and additional clinical experience as the primary reasons for entering SAS posts. Although these are without doubt benefits of holding the post I did not see them as reason enough for postponement of higher training. I entered staff grade because I had no alternative.

My feeling from discussion with senior colleagues is that times have changed. Previously doctors would work as staff grades to accumulate additional clinical experience or for other reasons, and enter higher training when they felt ready to do so. With the introduction of Modernising Medical Careers (MMC) competition has become more intense and there is a general feeling that in future it will be much more difficult if not impossible to re-enter training from career grade posts.

Although I have been lucky enough to secure one of the last NTNs it required numerous applications, more than would have been allowed under MMC. I have certainly benefited from pay protection and additional clinical experience, however I could not cite these as reasons for entering the grade in the first place.

Mark Fielding Staff Grade Doctor, Department of Old Age Psychiatry, St Martin's Hospital, Clara Cross Lane, Bath BA2 5RP, email: mark.fielding@ yahoo.co.uk

doi: 10.1192/pb.31.7.273a

\section{Teaching qualifications for psychiatrists}

Dinniss et al (Psychiatric Bulletin, March 2007, 31, 107-109) described their experience of the MSc in Clinical Education which they completed through the Peninsula Postgraduate Health Institute which is affiliated to the Universities of Exeter and Plymouth. My experience of pursuing a Postgraduate Certificate in Academic Practice (PGCAP) at King's Institute of Learning and Teaching (KILT) in London bears some similarities.

There is clearly an argument in favour of a formal training in postgraduate education or perhaps specifically clinical education. Specialist registrars/ST4 trainees might wish to enhance their skills and provide a better quality of teaching based on a strong theoretical background and practical experience.

The PGCAP has been a worthwhile experience, improving my teaching skills, knowledge of educational theory and facilitating reflective teaching practice. I have become more aware of issues relating to curriculum design and assessments. I believe this knowledge will be helpful for educational or clinical supervisory roles under Modernising Medical Careers.

Drawbacks of the PGCAP are that it is not discipline specific (although what has been learnt can easily be applied to all disciplines) and the course is expensive. To address the issue of discipline specificity, perhaps the College's Education and Training Centre might consider setting up a course aimed at psychiatric educators. Trusts could assist trainees with costs of courses through special budgets for medical education.

Chidinma Nwosu Specialist Registrar, Community Drug and Alcohol Team, 36/42 Hare Street, Woolwich SE18 6LZ, email: chidinma.nwosu@slam.nhs.uk

doi: 10.1192/pb.31.7.273b
I agree with Dinniss et al (Psychiatric Bulletin, March 2007, 31,107-109) that an MSc in Clinical Education is a worthwhile qualification, as there will be increasing pressure on senior clinicians to take an active part in teaching medical students and trainees. As society expects the healthcare system to be more and more transparent, clinicians will be held more accountable for their teaching and workplace-based assessments.

Learning to teach well means questioning the effectiveness of some of the old teaching methods, exploring new ideas and trying out new methods in different situations. Having started the MSc in Clinical Education in the past year, I find the experience extremely rewarding and enlightening. Being a product of the 'old system' of medical education where didactic teaching (lecture-based) dominated the curriculum, I found the principles of adult learning and the various techniques of small-group teaching quite fascinating. The feedback I received from medical students about the effectiveness of these techniques has been encouraging.

There is no doubt that there is an increasing demand for clinicians to deliver high-quality education, and a qualification in clinical education could become an essential rather than a desirable requirement for future consultant posts in the National Health Service.

AntonyThekkepalakkal Antony Specialist Registrar in Psychiatry, Devon Partnership NHS Trust, Wonford House Hospital, Exeter EX2 5AF, email: laluanto@yahoo.com

doi: 10.1192/pb.31.7.273c

Medical students are generally aware of the medical responsibilities that await than on qualification, but perhaps are not as aware of the inherent teaching responsibilities that will form an integral part of their professional duties. This is no different in psychiatry, and it is commonplace to expect psychiatric trainees to take responsibility for teaching medical students on attachments, despite having received minimal training in effective teaching methods.

Although I agree with the recommendation of Dinniss et al (Psychiatric Bulletin, March 2007, 31, 107-109) that an MSc in Clinical Education is a worthwhile qualification for consultant psychiatrists, I would argue that junior trainees in psychiatry should also be strongly encouraged to enhance their clinical teaching skills, as some trainees deliver as much teaching to medical students as their consultant colleagues.

The time constraints of combining an MSc with professional examinations could be avoided by undertaking a more manageable course such as the 1-year Higher Diploma in Clinical Teaching which is currently being offered by our 